minutes that gave the maximal result. The secretin test was considered abnormal if any one of these variables fell below the lower limits for control subjects.

There was little difference between the two tests (table I) and neither test was better than the other in the separation of chronic pancreatitis from pancreatic carcinoma (table II).

The results suggest that the Lundh test is likely to be more useful in clinical practice because of its practical advantages. The secretin test could be reserved for more complicated cases, eg, for some patients with coeliac disease.

References

Cook, H. B., Lennard-Jones, J. E., Sherif, S. M., and Wiggins, H. S.
(1967). Measurement of tryptic activity in intestinal juice as a diagnostic test of pancreatic disease. Gut, 8, 408-414.

Levin, G. E., Youngs, G. R., and Bouchier, I. A. D. (1972). Evaluation of the Lundh test in the diagnosis of pancreatic disease. J. clin. Path., 25, 129-132.

Lundh, G. (1962). Pancreatic exocrine function in neoplastic and inflammatory disease; a simple and reliable new test. Gastroenterology, 42, 275-280.

Lurie, B., Brom, B., Bank, S., Novis, B., and Marks, I. N. (1973). Comparative response of exocrine pancreatic secretion following a test meal and secretin-pancreozymin stimulation. Scand. J. Gastroent., 8, 27-32.

Mottalob, A., Kapp, F., Noguera, E. C. A., Kellock, T. D., Wiggins, H. S., and Waller, S. L. (1973). The Lundh test in the diagnosis of pancreatic disease: A review of five years' experience. Gut $14,835-841$.

Waller, Sheila L., Kapp, F., Mottaleb, A., Noguera, E. C. A., Kellock, T. D., and Wiggins, H. S. (1972). A preliminary comparison of the Lundh and secretin pancreozymin tests in the diagnosis of pancreatic disease. (Abstr.) Arch. Mal. Appar. dig., 61, 227C.

Zeitlin, I. J., and Sircus, W. (1974). Factors influencing duodenal trypsin levels following a standard test meal as a test of pancreatic function. Gut, 15, 173-179.

\title{
Endoscopic retrograde choledochopancreatography in the diagnosis of pancreatic disease
}

\section{P. R. SALMON}

\section{From Bristol Royal Infirmary}

The diagnosis of pancreatic disease remains difficult in spite of the recent advances afforded by fibreoptic endoscopy. The introduction of fibre-optic endoscopy (Hirschowitz, Curtiss, Peters, and Pollard 1958) and the subsequent development of a cannulating endoscope (Takagi, Go, Sugiura, Futagawa, and Hioki, 1969; Oi, Ichioka, and Takemoto, 1969; Oi, 1970; Takagi, Ikeda, Nakayama et al, 1970) have led to the widespread use of endoscopic retrograde choledochopancreatography (ERCP) in the diagnosis and management of pancreatic and biliary tract disease (Oi, 1970; Oi, Takemoto, and Nakayama, 1970; Oi, Kobayashi, and Kono, 1970; Takagi et al, 1970; Ogoshi, Tobita, and Hara, 1970; Fujita, Soma, and Kidokoro, 1970; Demling and Classen, 1970; Kasugai, Kuno, Aoki et al, 1971; Kobayashi, Tanaka, and Tsuneoka, 1971; Salmon, Brown, Htut, Burwood, and Read, 1971a; Cotton, Salmon, Blumgart, Burwood, Davies, Lawrie, Pierce, and Read, 1972; Blumgart, Salmon, Cotton, Davies, Burwood, Beales, Lawrie, Skirving, and Read, 1972; Kasugai, Kuno, Kobayashi, and Hattori, 1972; Burwood, Davies, Lawrie, Blumgart, and Salmon, 1973; Blumgart, Salmon, and Cotton, 1974). Clinically ERCP is of value both in suspected and in known pancreatic disease. It can provide simul- taneous information from both the biliary tract and the pancreas and therefore detect primary biliary tract disease and biliary complications of pancreatic disease. In addition, a more precise definition of pancreatic pathology is possible leading to the detection of complications such as pancreatic duct strictures, cysts, and calculi. Finally, additional procedures may be provided (the collection of pancreatic juice and cytology) or be indicated (eg, percutaneous transhepatic cholangiography, selective pancreatic angiography). These indications are set out in table I.

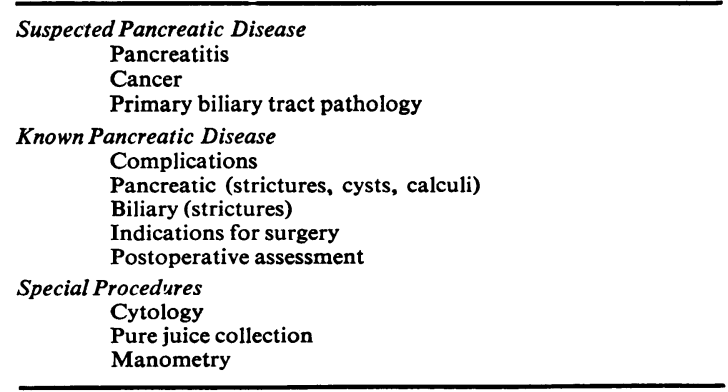

Table I Indications for ERCP in pancreatic disease 
The main problems involved in ERCP are (1) patient selection; (2) endoscopy technique and radiological management; and (3) interpretation of results.

The techniques required for choledocho-pancreatography are both endoscopic and radiographic so that close cooperation with an interested radiologist employing equipment of high quality invariably produces better results. The technical details of endoscopy are now widely agreed (Cotton and colleagues, 1972; Salmon and colleagues, 1972; Blumgart and Salmon, 1973; Salmon, 1974).

The examination is most often performed with a specialized duodenoscope (Olympus JFB-2, Machida FDS) but may also be performed with a suitable gastroduodenoscope, eg, the ACMI F5-A. Of particular value is the ability to examine the second part of the duodenum before cannulation. By this means distortion of the second part and periampullary cancer may be diagnosed and in the latter case confirmed by biopsy and brush cytology. The intramural bile duct may also be studied and lower bile duct obstruction may often be apparent when the duct is clearly distended.

It is essential to obtain a medical duodenal ileus for cannulation and this can be achieved by employing a suitable anticholinergic agent, namely, hyoscine-N-butyl bromide (Buscopan), or glucagon (0.5-1 mg intravenously). Foaming can be eliminated by a suitable silicone preparation (Salmon, 1974).

The prone position is usually employed for injections of contrast medium so that anteroposterior views are obtained with an under-couch tube.

Good radiological management provides the key for success in obtaining high quality choledochopancreatograms. An experienced radiographer and radiologist are essential and high quality image intensification facilities allow of the early detection of pancreatic duct filling and detail of the branch ducts (Bauerle, Grassman, Classen, and Demling, 1972) and parenchymal opacification. Parenchymography is generally to be avoided as the risk of precipitating acute pancreatitis is increased. A video tape recorder and/or a $100 \mathrm{~mm}$ camera may give additional information on the dynamics of duct filling and emptying whilst an overcouch tube should be available for delayed films (Burwood et al, 1973).

Good radiological management will include the choice of optimum contrast, eg, methylglucamine and sodium diatriazoate $60 \%$ (Urografin) or methylglucamine diatriazoate $65 \%$ (Angiografin) for pancreatography and sodium diatriazoate $25 \%$ (Hypaque) for choledochography (Burwood, 1974), the recognition of injected air bubbles, the correct positioning of the patient and early recognition of parenchymal filling, duct anatomy and congenital abnormalities. Selective catheterization of the bile duct after pancreatography can usually be achieved by withdrawing the catheter (whose tip is calibrated) until the tip is almost removed from the papillary orifice then angling the catheter tip upwards towards the patient's head before re-insertion. Selective catheterization, although usually possible by this means, may be difficult when there are either two orifices without a common channel or where there is a very short common channel.

Although successful cannulation of the relevant duct system can now be achieved in between 80 and $90 \%$ of cases, failures occur. These may be seen in patient intolerance (refusal, failed intubation), gastroduodenal disease (gastric volvulus, pyloric stenosis), Billroth II (Polya) gastrectomy, distorted second part of duodenum, periampullary diverticulum, Vaterian stenosis, ampullary carcinoma, and papillitis. In cases where the patient cannot tolerate the procedure it may be worthwhile making another attempt at a later date after discussion with the patient and perhaps using heavier sedation. In the case of Billroth II partial gastrectomy the afferent loop must be intubated, and a forward-viewing duodenoscope may be more suitable for these patients (Sáfrány, 1972). The problems of the accurate diagnosis and pathogenesis of papillitis and Vaterian stenosis have not yet been accurately worked out.

Whereas endoscopic cholangiography can now be considered to be the investigation of choice in the jaundiced patient where infusion cholangiography is either impracticable or has failed, the value of endoscopic pancreatography is more difficult to assess. There are a number of reasons for this, the most important being the relative difficulty in interpreting the pancreatogram.

The European Endoscopy Study Group has collected data from a number of European centres and shown the most common form of the normal pancreatogram (Cotton, 1973). The normal pancreas usually lies on the posterior abdominal wall crossing the first and second lumbar vertebrae obliquely, with the tail of the gland situated at a higher level than the head. There are as many as nine commonly recognized patterns in the overall shape of the gland although most take a pistol-shaped course (ascending-horizontal-horizontal form). These normal variations make it very difficult to diagnose pathological displacement of the duct. Duct lengths are difficult to measure accurately and are therefore probably of little value in diagnosis but duct diammeters may be of more value. Available data on maximum duct diameters in normal subjects are shown in figure 1 . There is general agreement that 
PANCREATIC DUCT WIDTH $(\mathrm{mm})$

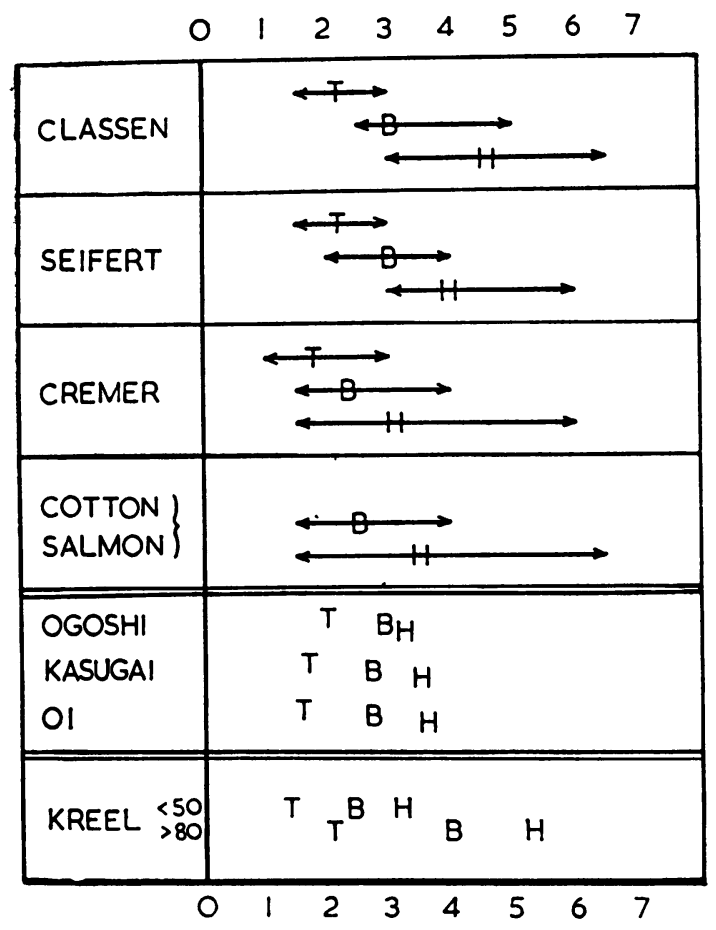

Fig 1 Normal pancreatic duct widths. Median values with range collected from various centres and from the literature (Cotton, 1973)

average normal diameters are $4 \mathrm{~mm}, 3 \mathrm{~mm}$, and $2 \mathrm{~mm}$ in the head, body, and tail of the gland respectively. Maximum diameters measured in postmortem material tend to be greater (Millbourn, 1960;
Kreel, Sandin, and Slavin, 1973), probably due to a combination of age, postmortem artefact, and possibly radiographic magnification. Age alone did not appear to be a significant factor in the European study group (fig 2). An additional difficulty may be presented by local anatomical structures such as the splenic vessels, superior mesenteric artery, osteophytes, and lymph nodes which can alter the pancreatogram. Subtraction films may sometimes help to evaluate these difficult cases.

\section{Pancreatitis}

The value of ERCP in pancreatitis lies in the demonstration of structural changes in the ducts, the presence of complications (strictures, cysts, stones) and the demonstration of accompanying biliary disease-gallstones and common duct obstruction (fig 3). Although the value of surgical drainage procedures in chronic pancreatitis is controversial, a preoperative demonstration of duct anatomy may be of value to the surgeon (Trapnell, 1974), and follow up of cases subjected to pancreatic surgery may establish whether drainage has been successful or not. Nakajima, Tada, Sugawara, Kato, and Kawai (1973) have demonstrated in a small study that there is a correlation between endoscopic pancreatography and histology obtained at surgical biopsy. Kasugai, Kuno, and Kizu (1974) have extended their experience of pancreatitis and have now performed ERCP on 255 patients with chronic pancreatitis. Of this series 117 were regarded as minimal change pancreatitis, 97 as moderate, and 41 as advanced pancreatitis (table II). Although it is often relatively easy to diagnose pancreatitis on pancreatography it is sometimes difficult to differentiate minimal changes from normal, and at the other

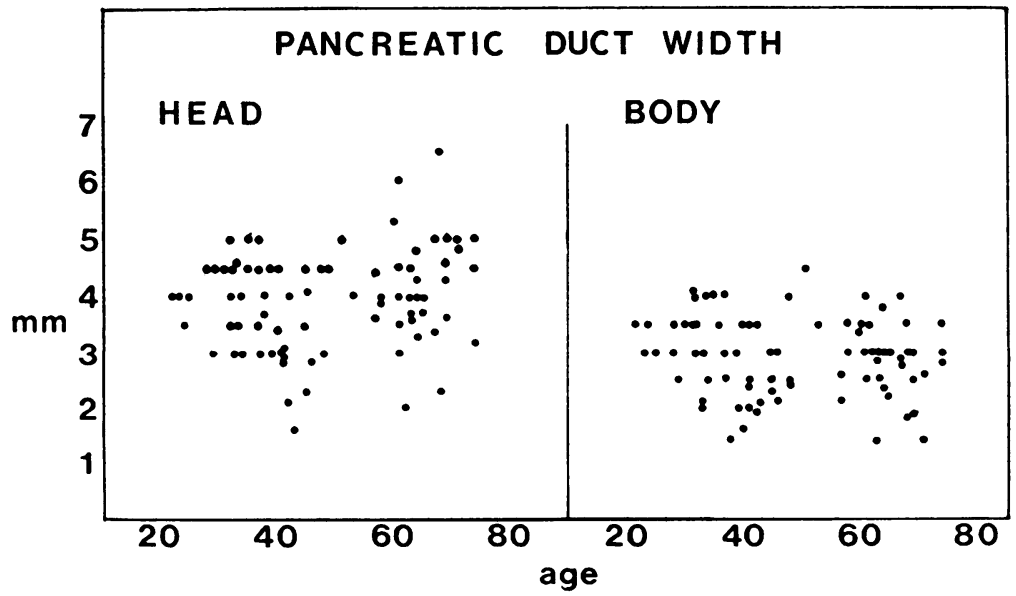

Fig 2 Comparison of age and pancreatic duct width in subjects with normal pancreas measured from the head and body of the gland: $\mathrm{r}=0.176, \mathrm{P}>0.05$, head; $\mathrm{r}=0 \cdot 144, \mathrm{P}>0.05$, body. (From Cotton, 1973) 


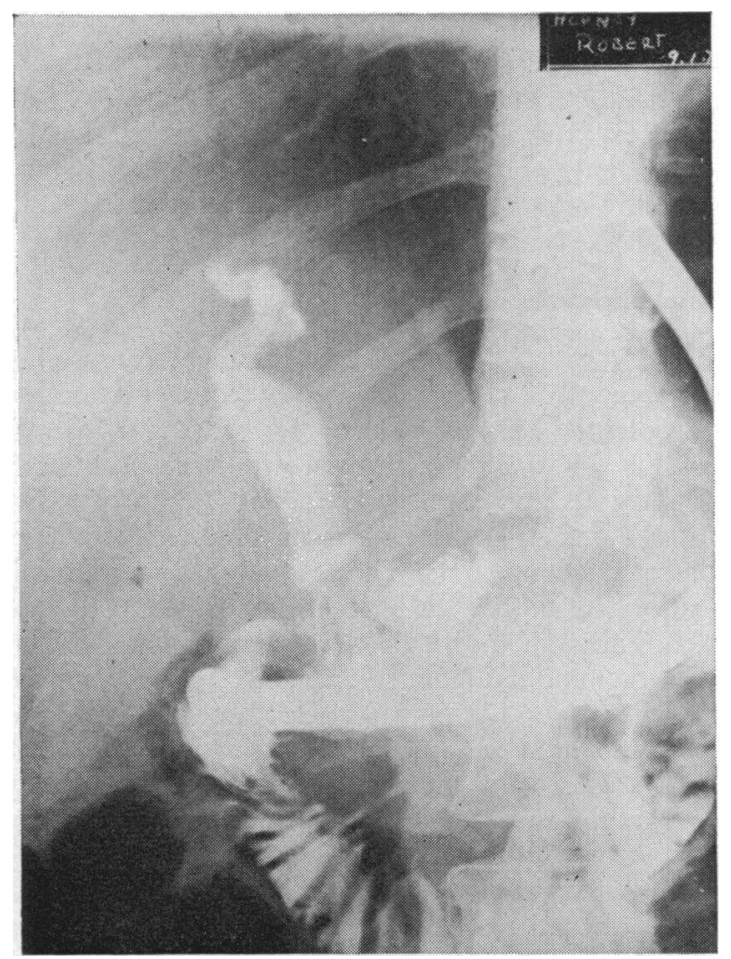

Fig 3 Chronic pancreatitis with stricture of lower common bile duct. Note proximal dilatation of biliary system and gross disorganization of pancreatic duct ('chain of lakes' appearance)

extreme to differentiate cancer from pancreatitis. Both in fact may coexist. Cotton and Beales (1974) demonstrated a surgical lesion(stricture, obstruction, or cyst) in nearly half of a group of 31 cases of recurrent pancreatitis.

A comparison of pancreatography with exocrine function studies (Salmon, 1975a) has shown that minimal change pancreatitis may be associated with a normal maximum bicarbonate but a decreased trypsin output. A further feature of minimal change lesions is an elevated fasting serum cholecystokinin level as measured by radioimmunoassay (Harvey, 1975).

\section{Pancreatic Cancer}

Most series show between 5 and $10 \%$ of their total ERCP cases to have pancreatic carcinoma but comparison is difficult due to varying methods of case selection. Kasugai et al (1972b) demonstrated carcinoma in 14 of 380 cases (5\%) and a similar figure was obtained from 54 of 1082 examinations published from Budapest and Bonn (Stadelmann, Sáfrány, Barna, Miederer, Papp, Kaufer, and Sobbe,

\begin{tabular}{|c|c|c|c|}
\hline & \multicolumn{3}{|c|}{ Pancreatitis } \\
\hline & $\begin{array}{l}\text { Minimal } \\
\text { Change }\end{array}$ & Moderate & Marked \\
\hline \multicolumn{4}{|l|}{$\begin{array}{l}\text { Pancreas } \\
\quad \text { Main pancreatic duct }\end{array}$} \\
\hline Rigidity & \pm & + & $+t$ \\
\hline Tortuosity & \pm & + & ++ \\
\hline Irregular calibre & $=$ & + & $+t$ \\
\hline Obstruction & - & - & + \\
\hline Cyst formation & - & - & + \\
\hline Calculi & - & - & + \\
\hline \multicolumn{4}{|l|}{ Branch ducts } \\
\hline Rigidity & + & ++ & ++ \\
\hline Irregular distribution & + & ++ & ++ \\
\hline Dilatation & + & $+t$ & ++ \\
\hline Irregular calibre & + & ++ & ++ \\
\hline Cystic dilatation & - & + & ++ \\
\hline Calculi & - & - & + \\
\hline \multicolumn{4}{|l|}{ Parenchyma } \\
\hline Coarse opacification & - & - & + \\
\hline \multicolumn{4}{|l|}{ Size of pancreas } \\
\hline \multirow{2}{*}{\multicolumn{4}{|c|}{$\begin{array}{l}\text { Biliary System } \\
\quad \text { Lower common bile duct }\end{array}$}} \\
\hline & & & \\
\hline Rigidity & - & + & ++ \\
\hline Dilatation & - & + & ++ \\
\hline Stenosis & - & + & ++ \\
\hline Irregularity & - & - & + \\
\hline
\end{tabular}

Table II Criteria for ERCP in the diagnosis of chronic pancreatitis $^{1}$

'After Kasugai, Kuno, and Kizu (1974)

1974). In our own series in Bristol (Salmon, 1975b) 40 cases of pancreatic cancer were diagnosed out of a total of 450 examinations. There are insufficient data at present to show that 'early' diagnosis of pancreatic cancer can be effected by ERCP but the results of increased experience in the interpretation of pancreatograms coupled with pancreatic cytology (Shida, 1973; Hatfield, Whittaker, and Gibbs, 1974) may produce better results. What is already clear, however, is that the clinical management of the patient may be influenced by ERCP. The decision to perform pancreaticoduodenectomy or a palliative choledochoenterostomy may be based on the results of ERCP. Several authors, such as Ogoshi and Hara (1972) and Stadelman, Sáfrány, Löffler, Barna, Miederer, Papp, Käufer, and Sobbe (1974), divide the duct changes in pancreatic cancer into several types, depending on whether there is a main duct stricture with proximal dilatation (fig 4), an interruption of contrast material (fig 5), complete obstruction (fig 6), tapering obstruction due to an acinar cell carcinoma, or cavernous filling of the gland parenchyma with obstruction. Although it is useful to recognize the various forms pancreatic cancer can take, there is no evidence at present that classifying pancreatic cancer in this manner has altered the prognosis of this disease.

Endoscopic retrograde choledochopancreato- 


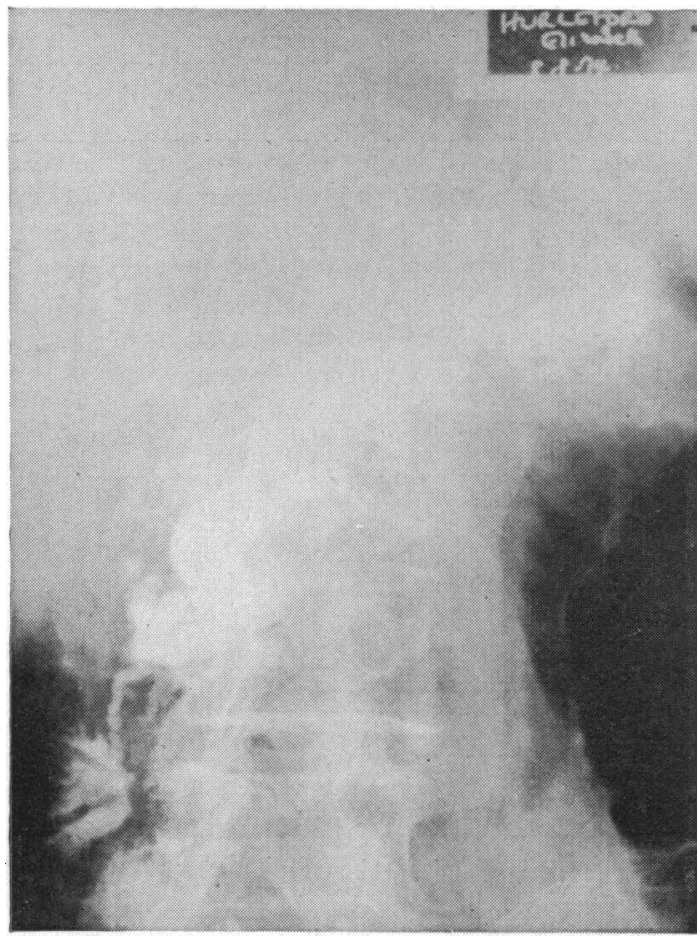

Fig 4 Carcinoma of head of pancreas. Note long stricture in head of gland with gross proximal dilatation

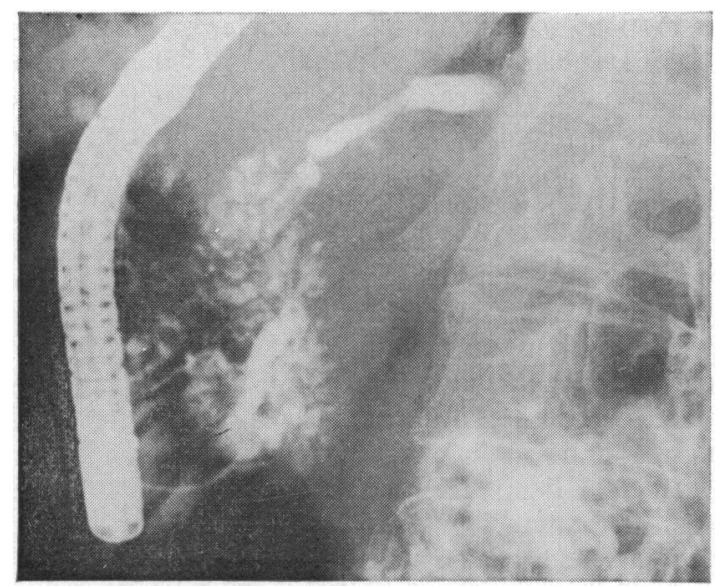

Fig 5

Fig 5 Carcinoma of body of pancreas. Interruption of contrast material, spotty parenchymal filling, and proximal irregularity with dilatation of the main pancreatic duct

Fig 6 Carcinoma of pancreas. Complete obstruction of pancreatic duct at junction of head and body of gland graphy should not be used alone to exclude pancreatic cancer but should be related to other investigations such as scintigraphy, pancreatic cytology, exocrine function studies, and more recently echotomography employing a grey-scale video system (Bekaert, Afschrift, Colardyn, and Eleivaut, 1975).

\section{Complications}

Endoscopic retrograte choledochopancreatography is essentially a safe procedure, but there are a number of potential and real hazards. These are: the hazards of the additional medication required for ERCP; cholangitis and septicaemia, transmission of hepatitis, damage to the papilla of Vater, pancreatitis, infected pseudocysts, and radiation. The complications of upper gastrointestinal fibreoptic endoscopy are well known and are generally rare (Schiller, Cotton, and Salmon, 1972). The specific complications of ERCP may include those attributed to additional medication such as anticholinergic drugs. Cholangitis and Gram-negative septicaemia may occur in about $2 \%$ of patients with jaundice subjected to ERCP but only when there is preexisting obstructive biliary disease. The use of prophylactic antibiotics is not clearly defined in this situation, whether administered parenterally or directly into the bile duct at endoscopic choledochography.

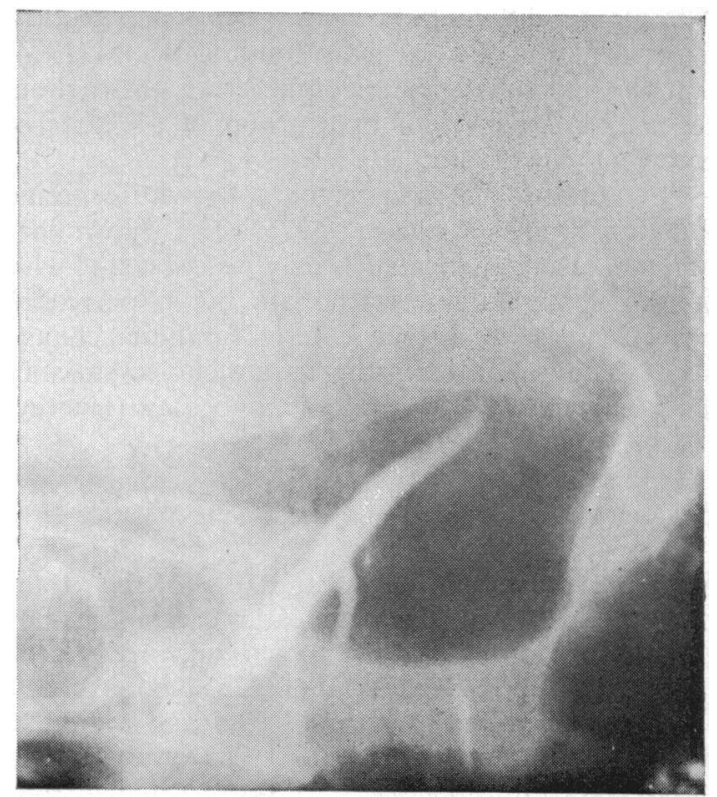

Fig 6 
The transmission of hepatitis has not been recorded but it is a wise precaution to demand a negative hepatitis antigen $(\mathrm{HbAg})$ report in patients with chronic hepatobiliary disease. Pancreatitis is rare following endoscopic pancreatography (less than $2 \%$, though transient hyperamylassaemia occurs in 40 to $45 \%$ of patients. One case of fatal necrotizing pancreatitis was reported by Ammann, Deyhle, and Butikofer (1973) following ERCP in a patient with relapsing acute pancreatitis. Pancreatic cysts should not be filled with contrast material unless surgery is planned within 24 to 28 hours since cysts which do not drain freely rapidly become infected following pancreatography.

$X$-irradiation during ERCP is low (about 10\% of that employed for infusion cholangiography). However, cumulative $x$-ray damage to the fibre bundles eventually occurs. Replacing these bundles is expensive and may cost as much as $30 \%$ of the price of a new instrument.

\section{References}

Ammann, R. W., Deyhle, P., and Butikofer, E. (1973). Fatal necrotizing pancreatitis after per-oral cholangiopancreatography. Gastroenterology, 64, 320.

Bauerle, H., Grassman, P. H., Classen, M., and Demling, L. (1972). The use of radiographic techniques in gastroenterological endoscopy. Electromedia, 4, 109.

Bekaert, S., Afschrift, M., Colardyn, F., and Eleivaut, A. (1975) Tomoechography of the pancreas". Proceedings of the 2nd International Symposium of Digestive Endoscopy (Belgian Society of Digestive Endoscopy), Brussels. (Abstr.)

Blumgart, L., and Salmon, P. (1973). Fiber duodenoscopy and transpapillary cholangiopancreatography. In Recent Advances in Surgery. Churchill, Livingstone, London.

Blumgart, L. H., Salmon, P. R., and Cotton, P. B. (1974). Endoscopy and retrograde choledochopancreatography in the diagnosis of the patient with jaundice. Surg. Gynec. Obstet., 138, 565570.

Blumgart, L. H., Salmon, P., Cotton, P. B., Davies, G. T., Burwood, R., Beales, J. S. M., Lawrie, B., Skirving, A., and Read, A. E. (1972). Endoscopy and retrograde choledochopancreatography in the diagnosis of the jaundiced patient. Lancet, 2, 1269.

Burwood, R. J. (1974). The role of radiology in fibre-optic endoscopy. In Fibre-optic Endoscopy, by P. R. Salmon p. 183. Pitman, London.

Burwood, R. J., Davies, G. T., Lawrie, B. W., Blumgart, L. H., and Salmon, P. R. (1973). Endoscopic retrograde choledochopancreatography: a review with a report of a collaborative series. Clin. Radiol., 24, 397-415.

Cotton, P. B. (1973). The normal endoscopic pancreatogram. Endoscopy, 6, 65-70.

Cotton, P. B., and Beales, J. S. (1974). Endoscopic pancreatography in management of relapsing acute pancreatitis. Brit. med. J. 608-611.

Cotton, P. B., Salmon, P. R., Blumgart, L. H., Burwood, R. J., Davies, G. T., Lawrie, B. W., Pierce, J. W., and Read, A. E. (1972). Cannulation of papilla of Vater via fiber-duodenoscope: assessment of retrograde cholangiopancreatography in 60 patients. Lancet, $1,53$.

Demling, L., and Classen, M. (1970). Duodenojejunoskopie. Dtsch. med. Wschr., 95, 1427.

Fujita, R., Soma, S., and Kidokoro, 1. (1970). Endoscopy of the duodenum (experience using Olympus Jf-2). Gastroent. Endosc., 12, 97

Harvey, R. F. (1975). Personal communication.

Hatfield, A. R. W., Whittaker, R., and Gibbs, D. D. (1974). The collection of pancreatic fluid for cytodiagnosis using a duodenoscope. Gut, 15, 305-307.

Hirschowitz, B. I., Curtiss, L. E., Peters, C. W., and Pollard, H. M. (1958). Demonstration of a new gastroscope, the 'Fiberscope'. Gastroenterology, 35, 50.

Kasugai, T., Kuno, N., Aoki, I. (1971). 'Fiber duodenoscopy analysis of 353 examinations.' Gastrointestinal Endoscopy, 18, 9 ,

Kasugai, T., Kuno, N., Kobayashi, S., and Hattori, K. (1972a.) Endoscopic pancreatocholangiography. 1. The normal endoscopic pancreatocholangiogram. Gastroenterology, 63. 227-234.

Kasugai, T., Kuno, N., Kizu, M., Kobayashi, S., and Hattori, K. (1972b). Endoscopic pancreatocholangiography. 2. The pathological endoscopic pancreatocholangiogram. Gastroenterology, 63, 227.

Kasugai, T., Kuno, N., and Kizu, M. (1974). Endoscopic cholangiopancreatography. Stomach and Intestine (Tokyo), 8, 3-8.

Kobayashi, M., Tanaka, N., and Tsuneoka, K. (1971). Retrograde cholangiography with duodenoscope. Baika, 27, 629.

Kreel, L., Sandin, B., and Slavin, H. (1973). Pancreatic morphology: a combined radiological and pathological study. Clin. Radiol. 24,154 .

Millbourn, E. (1960) Calibre and appsarance of the pancreatic ducts and relevant clinical problems. Acta chir. scand., 118, 286.

Nakajima Tada, Sugawara, Kato, and Kawai (1973). Endoscopic pancreatography. Stomach and Intestine (Tokyo), 8, 3.

Ogoshi, K., and Hara, Y. (1972). Retrograde pancreato-choledochography. Jap. J. clin. Radiol., 17, 455.

Ogoshi, K., Tobita, Y., and Hara, Y. (1970). Endoscopic observation of the duodenum and pancreato-choledochography using duodenal fiberscope under direct vision. Gastroent. Endoscopy (Tokyo), 12, 83 .

Oi, I. (1970). Endoscopic pancreato-cholangiography. Saishin Igaku, 25, 2292.

Oi, I., Ichioka, S., and Takemoto, T. (1969). Intestinal endoscopy: chiefly on the present status of endoscopic examination of the duodenum. Stomach and Intestine (Tokyo), 4, 469.

Oi, I., Kobayashi, S., and Kondo, T. (1970a). Endoscopic pancreatocholangiography. Endoscopy, 2, 103.

Oi, I., Takemoto, T., and Nakayama, K. (1970b). Fiberduodenoscopy-early diagnosis of cancer of the papilla of Vater. Surgery, 67, 561 .

Sáfrány, L. (1972). Endoscopy and retrograde cholangio-pancreatography after Billroth II operation. Endoscopy, 4, 198.

Salmon, P. R. (1975a). Pancreatic function and its relation to pancreatography. In 2nd International Symposium of Digestive Endoscopy (Belgian Society of Digestive Endoscopy), Brussels. (Abstrs.)

Salmon P. R. (1975b). Early diagnosis of pancreatic cancer. Proceedings of the 11th Symposium on Advanced Medicine. Pitman, London.

Salmon, P. R. (1974). Fibre-optic Endoscopy. Pitman Medical, London. Salmon, P. R., Brown, P., Htut, T., Burwood, R., and Read, A. E. Duodenoscopy. 1971 (Letter) Lancet, 1, 1298-1299.

Salmon, P. R., Brown, P., Thein-Htut, and Read, A. E. (1972). Endoscopic examination of the duodenal bulb: clinical evaluation of forward and side viewing fibreoptic systems in 200 cases. Gut, 13, 170-175.

Salmon, P. R., Blumgart, L., Burwood, R., Davies, G., and Read, A. E. (1973). Endoscopy in the diagnosis of obstructive jaundice. In Endoscopy of the Small Intestine with Retrograde Pancreato-cholangiography, edited by L. Demling and $\mathbf{M}$. Classen, p. 98. Thieme, Stuttgart.

Schiller, K. F. R., Cotton, P. B., and Salmon, P. R. (1972). Hazards of routine upper gastro-intestinal endoscopy: a review of British experience. In Proceedings of the 2nd European Congress of Digestive Endoscopy, Paris.

Shida, M. (1973). Personal communication.

Stadelmann, O., Sáfrány, L., Löffler, A., Barna, L., Miederer, S. E., Papp, J., Käufer, C., and Sobbe, A. (1974). Endoscopic retrograde cholangiopancreatography in the diagnosis of pancreatic cancer. Endoscopy, 6, 84-93.

Takagi, T., Go, T., Sugiura, M., Futagawa, S., and Hioki, R. (1969). Fiberoptic duodenoscopy. Surgery, 65, 597.

Takagi, K., Ikeda, S., Nakagawa, Y. et al (1970). Retrograde pan. creatography and cholangiography by fiberduodenoscopeGastroenterology, 59, 445.

Trapnell, J. (1974). Personal communication. 